\title{
An Open Trial of Low Doses of Dapsone in the Management of Lepromatous Leprosy*
}

\author{
A. B. A. KARAT \\ Consultant Physician \\ A. JEEVARATNAM \\ Assistant Physician \\ P. S. S. RAO \\ Consultant Biostatistician \\ Schieffelin Leprosy Research Sanatorium, Karigiri, Tamilnadu, S. India
}

\begin{abstract}
This paper reports the results of treating patients with lepromatous leprosy with low doses of dapsone (5 or $10 \mathrm{mg}$ per day). The incidence of ENL seemed to be little affected but the severity of the reactions was generally less. There was little or no change in the morphological index, but the bacillary index showed a disturbing tendency to rise. The possible significance of these findings and the lesson to be drawn therefrom are discussed.
\end{abstract}

\section{INTRODUCTION}

Leprosy remained the "Cinderella" of medicine for centuries until, some 25 years ago, a specific anti-bacterial agent in the form of a sulphone derivative was first introduced in the treatment of the disease, with striking and spectacular success. Thanks to the early reports of Faget et al. (1943) from Carville, the introduction of promin (promanide) as a specific anti-leprosy drug opened a new era for patients with leprosy. Since then, much experience has been gained in the management of all types of leprosy with sulphones and there has been a considerable change in the thinking of leprologists regarding the optimum dose of sulphone in the management of leprosy (Muir, 1944; Faget and Pogge, 1944, 1945; James et al., 1967).

A further refinement was introduced by Shepard and Chang (1967) and later extended by Rees (1967) in the form of the mouse foot-pad technique to test the effectiveness of DDS against Mycobacterium leprae and to determine the minimum inhibitory dose of DDS in the mouse foot-pad system which would prevent multiplication of this organism. This technique provided for the first time a system outside man which lends itself to careful quantitative evaluation of therapeutic regimes claimed to be

\footnotetext{
*Received for publication 9 April, 1969.
}

beneficial in the management of leprosy. On the basis of these studies it was suggested that doses of sulphone of the order of 1 to $5 \mathrm{mg}$ per day would be adequate in the treatment of leprosy patients (Shepard, 1967; Waters et al., 1968). During the last 15 years it has been standard practice to treat patients with a maximum dose of $100 \mathrm{mg}$ of dapsone per day or $600 \mathrm{mg}$ per week in divided doses. Further, clinicians have gained the impression that patients treated with sulphones were getting quite severe episodes of erythema nodosum leprosum (ENL) with or without acute neurological catastrophes (Cochrane, 1963). It was also clear that since the introduction of sulphones the incidence of reactions among those with lepromatous leprosy has risen considerably, in contrast to the incidence of such reactions in the pre-sulphone era (James et al., 1967; Shepard, 1967).

It was suggested that the phenomenon of ENL might be dose-related and therefore early trials were initiated to study the effect of small doses of sulphone, in the region of 100 to $200 \mathrm{mg}$ per week in divided doses (Browne, 1965; Ramu and Ramanujam, 1965; Pettit and Rees, 1967). Waters et al. (1968), in a pilot trial, demonstrated that when administered in a dose of $1 \mathrm{mg}$ per day, DDS was able to reduce the morphological index (MI) in skin smears from leprosy patients very rapidly, that is, at a 
rate comparable to that seen in patients on $100 \mathrm{mg}$ of DDS, the conventional dose. In the present study at the Schieffelin Leprosy Research Sanatorium, Karigiri, we have investigated the therapeutic efficacy of 2 low dosage levels of DDS in lepromatous leprosy: (1) $5 \mathrm{mg}$ of dapsone 6 times per week (30 $\mathrm{mg}$ per week) and (2) $10 \mathrm{mg}$ of dapsone daily (60 $\mathrm{mg}$ per week). We were particularly concerned with the change in the MI, the rate of clearance of bacilli, the incidence and severity of ENL in relation to small doses of DI)S, the changes in the peripheral nerve functions during treatment, and the over-all clinical improvement or worsening in patients on these small doses. In this paper the changes in the MI and bacterial index (BI), the clinical responses, and the incidence of ENL are presented for patients who have been followed for a minimum period of one year. The results presented here should be considered as still preliminary.

\section{MATERIALS AND METHOD}

A total of 20 patients with lepromatous leprosy have so far been carefully followed up for at least one year. Of these, 12 received $5 \mathrm{mg}$ of DDS per day on 6 days per week (total $30 \mathrm{mg}$ per week), and 8 patients were given $10 \mathrm{mg}$ of DDS per day (total $60 \mathrm{mg}$ of DDS per week). The data on MI were recorded according to Shepard's criteria. The BI and the reaction status were determined carefully and recorded periodically, along with the clinical status of the skin lesions and the general condition of the

TABLE 1

Changes in BI and MI for patients on $5 \mathrm{mg}$ of DDS per day

\begin{tabular}{|c|c|c|c|c|c|c|c|}
\hline $\begin{array}{c}\text { Case } \\
\text { no. }\end{array}$ & $\begin{array}{l}\text { Initial } \\
\text { value }\end{array}$ & $\begin{array}{c}\text { BI } \\
\text { Firial } \\
\text { value }\end{array}$ & $\begin{array}{c}\text { Initial } \\
\text { minus } \\
\text { final }\end{array}$ & $\begin{array}{c}\text { No. of days } \\
\text { on DIDS }\end{array}$ & $\begin{array}{c}\text { Initial } \\
\text { value } \\
\%\end{array}$ & $\begin{array}{c}\text { MI } \\
\text { F'inal } \\
\text { value } \\
\%\end{array}$ & $\begin{array}{l}\text { Initial } \\
\text { minus } \\
\text { final }\end{array}$ \\
\hline 1 & 3.75 & 4.12 & -0.37 & 439 & 0 & 0.50 & -0.50 \\
\hline 2 & 1.37 & 2.25 & -0.88 & 472 & 0.50 & 0 & +0.50 \\
\hline 3 & 2.87 & 3.87 & -1.00 & 567 & 3 & 0.37 & +2.63 \\
\hline 6 & 1.25 & 2.87 & -1.62 & 492 & 0.50 & 0 & +0.50 \\
\hline 7 & 3.50 & 3.00 & +0.50 & 432 & 0 & 0 & 0 \\
\hline 8 & 3.00 & 3.75 & -0.75 & 540 & 0.50 & 0.37 & +0.13 \\
\hline 9 & 2.62 & 3.25 & -0.63 & 596 & 0.25 & 0 & +0.25 \\
\hline 10 & 3.00 & 3.25 & -0.25 & 569 & 1 & 0.12 & +0.88 \\
\hline
\end{tabular}

TABLE 2

Changes in BI and MI for patients on $10 \mathrm{mg}$ of DDS per day

\begin{tabular}{|c|c|c|c|c|c|c|c|}
\hline $\begin{array}{c}\text { Case } \\
\text { no. }\end{array}$ & $\begin{array}{l}\text { Initial } \\
\text { value }\end{array}$ & $\begin{array}{l}\quad \text { RI } \\
\text { Final } \\
\text { value }\end{array}$ & $\begin{array}{l}\text { Initial } \\
\text { minus } \\
\text { final }\end{array}$ & $\begin{array}{c}\text { No. of days } \\
\text { en DIDS }\end{array}$ & $\begin{array}{c}\text { Initial } \\
\text { value } \\
\%\end{array}$ & $\begin{array}{c}M I \\
\text { Hinal } \\
\text { value } \\
\%\end{array}$ & $\begin{array}{l}\text { Initial } \\
\text { minus } \\
\text { final }\end{array}$ \\
\hline 13 & 1.75 & 2.75 & -1.00 & 506 & () & 0.12 & -0.12 \\
\hline 14 & 2.37 & 2.87 & -0.50 & 498 & 3.50 & 0 & +3.50 \\
\hline 15 & 1.12 & 0.87 & +0.25 & 1033 & () & () & () \\
\hline 16 & 3.25 & 3.62 & -0.37 & 513 & () & () & () \\
\hline 17 & 2.37 & 3.25 & -0.88 & 513 & 0.50 & 0.75 & -0.25 \\
\hline 18 & 2.50 & 2.25 & +0.25 & 444 & 0 & 0 & () \\
\hline 19 & 3.62 & 3.62 & () & 453 & 0.75 & 0.25 & +0.50 \\
\hline 20 & 2.25 & 3.25 & -1.00 & 574 & () & 0.5 & -0.50 \\
\hline
\end{tabular}


patient as a whole. When any of the patients in this trial developed a reaction, we attempted to maintain them on the dose of DDS they weie getting at the time they went into "reaction", and tried to control the reaction with the conventional anti-inflammatory drugs such as chloroquine, stibophen, aspirin, etc. Unless the clinical condition deteriorated so as to make it necessary for us to intervene with a more potent anti-inflammatory drug we did not change the DDS dosage in these patients. This was a departure from our usual policy of stopping dapsone treatment in patients who developed ENL, but we did so in order to test the opinion that has been expressed that dapsone has probably nothing to do with the precipitation of exacerbation in lepromatous leprosy.

\section{RESULTS}

\section{$M I$ and $B I$}

The changes in the MI and BI in the 12 patients receiving $5 \mathrm{mg}$ DDS per day are shown in Table 1 , and those in the 8 patients taking $10 \mathrm{mg}$ of DDS per day are shown in Table 2.

TABLE 3

Changes in MI during therapy

\begin{tabular}{lccc}
\hline Change in MI & \multicolumn{3}{c}{ DDS per day } \\
& $5 \mathrm{mg}$ & $10 \mathrm{mg}$ & Total \\
\hline $\begin{array}{l}\text { Initial value zero, remained at } \\
\quad \text { zero }\end{array}$ & 1 & 3 & 4 \\
$\begin{array}{l}\text { Declined to zero } \\
\text { Declined significantly but did } \\
\quad \text { not reach zero }\end{array}$ & 5 & 1 & 6 \\
$\begin{array}{l}\text { Recorded increases but within } \\
\quad 0.5 \%\end{array}$ & 5 & 1 & 6 \\
Total & 12 & 3 & 4 \\
\hline
\end{tabular}

The changes in the MI are further summarized and presented in Table 3. It is obvious from this table that the MI declined, and in many instances become zero, in patients treated with these small doses of DIS. The changes in the BI recorded at the last follow-up examination were compared with the initial values at the beginning of therapy and are presented for patients on $5 \mathrm{mg}$ DIDS per day (Fig. 1 (a)) and on $10 \mathrm{mg}$ DDS per day (Fig. 1 (b)).

The increases or decreases from the initial value are summarized and presented in Table 4 .

$$
\text { TABLE } 4
$$

Changes in BI during therapy

\begin{tabular}{llccc}
\hline $\begin{array}{l}\text { Changes in BI } \\
\text { from initial value }\end{array}$ & \multicolumn{4}{c}{ DDS per day } \\
from & $5 \mathrm{mg}$ & $10 \mathrm{mg}$ & Total \\
\hline $\begin{array}{l}\text { Increased or } \\
\text { same }\end{array}$ & $\begin{array}{l}0.5 \text { and less } \\
0.6 \text { to } 0.9\end{array}$ & 4 & 3 & 7 \\
& 1.0 and more & 3 & 1 & 4 \\
& No. increased & 10 & 6 & 16 \\
Decreased & 0.5 and less & 2 & 2 & 4 \\
& No. decreased & 2 & 2 & 4 \\
Total studied & & 12 & 8 & 20 \\
\hline
\end{tabular}

From this table it can be seen that $16(80 \%)$ of the patients showed either no significant change or an increase in the BI from the initial value. Whatever decreases there were are rather small, considering the duration of therapy.

It is interesting to observe the changes in the BI during therapy. While there are considerable variations in the individual responses, one

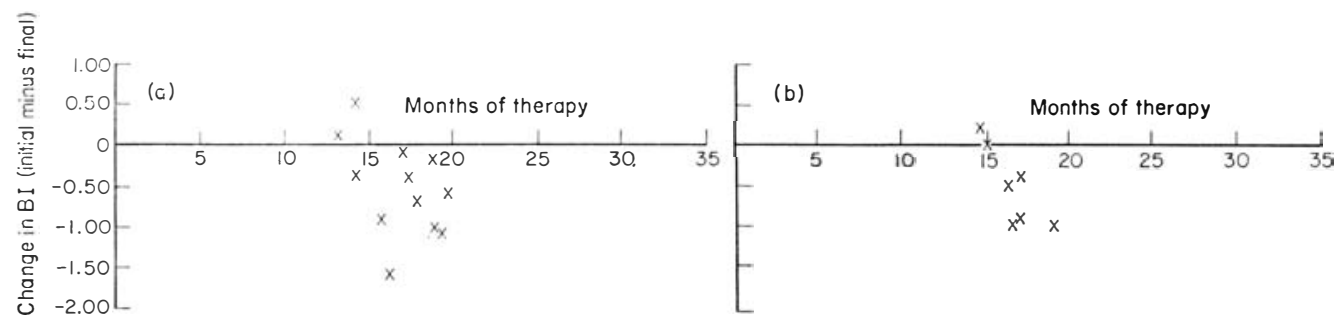

Fig. 1

Change in BI at the last follow-up treatment: (a) DIDS $5 \mathrm{mg}$; (b) DDDS $10 \mathrm{mg}$. 
might try to fit the changes into one of the following 4 categories: (1) fluctuations throughout the course of therapy, with no change in the BI at the time of reporting; (2) an initial decline in the BI followed by an increase, with some fluctuations; (3) a continual increasing BI with minor fluctuations; and (4) a constantly declining index with some fluctuations.

The number of patients falling into each of the 4 patterns in the 2 treatment groups is shown in Table 5.
TABLE 5

Patterns of change in BI during therapy

\begin{tabular}{lccc} 
Pattern of change & \multicolumn{3}{c}{ DDS per day } \\
& $5 \mathrm{mg}$ & $10 \mathrm{mg}$ & Total \\
\hline (1) No significant change & 5 & 1 & 6 \\
(2) Initial decline, later rise & 3 & 4 & 7 \\
(3) Continual rise & 4 & 3 & 7 \\
(4) Constant decline & & & \\
Total & 12 & 8 & 20
\end{tabular}
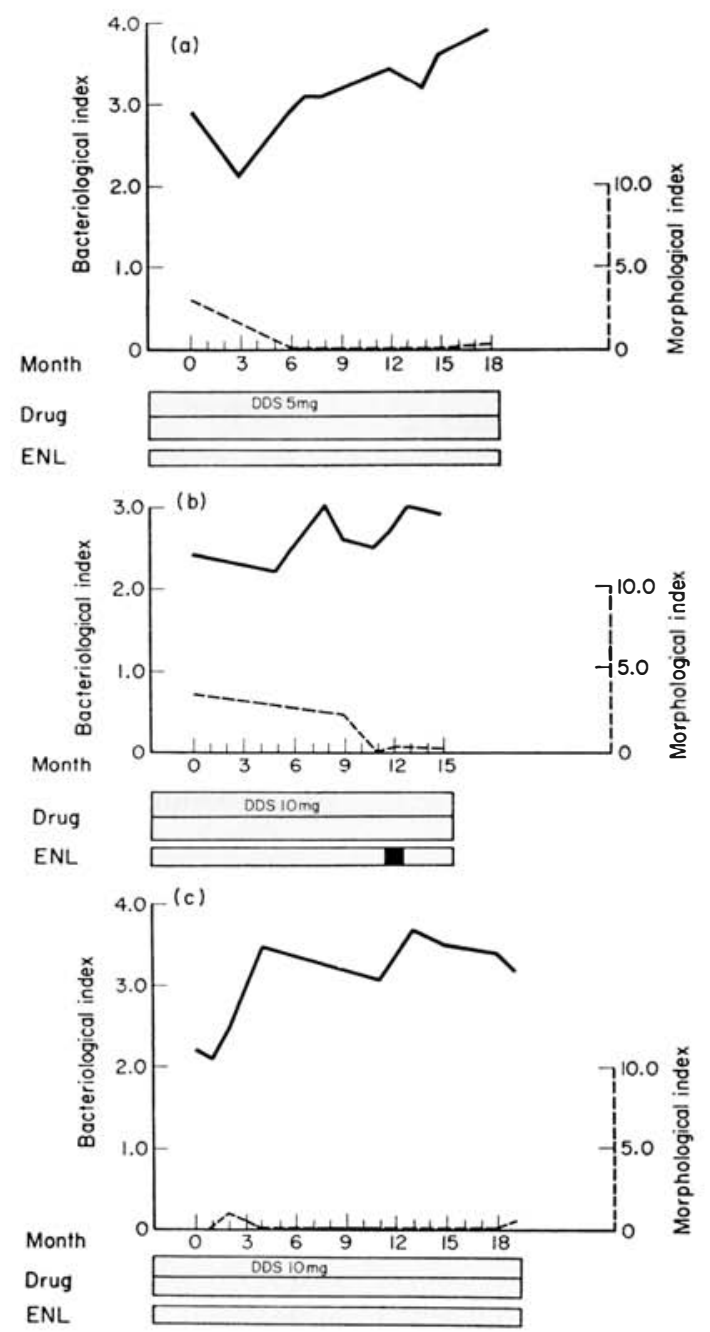

Fig. 2

Response to low dose DDS. Case no. (a) 3; (b) 14; (c) 20. 
All the responses fall in patterns 1,2 or 3 , depicting either no change or an increase in the BI. No patient showed the fourth pattern of a constantly declining bacterial index. However, there was one patient in the DDS $10 \mathrm{mg}$ per day group for whom a decline in the BI to zero was recorded, but this case has subsequently shown increases even while continuing the therapy. The changes in $\mathrm{BI}$ and $\mathrm{MI}$ in 3 sample cases are depicted in Fig. 2 (a, b, c).

\section{Changes in clinical features}

In this study none of the 20 patients has shown any significant improvement in the appearance of skin lesions. On the other hand, none of the patients showed any striking deterioration in terms of the clinical appearance of skin lesions and of systemic disturbance.

\section{ENL}

The episodes of reactions (ENL syndrome) observed in the 20 patients while receiving treatment with low doses of DDS are summarized in Table 6, which shows that out of the 20 patients 7 had "reactions" (ENL). These reactions, however, responded fairly satisfactorily to anti-inflammatory therapy without discontinuing the DDS therapy, and except for 3 cases in the 5-mg group the "reactions" did not recur.

\section{TABLE 6}

Reactions during therapy

\begin{tabular}{cccc}
\hline Reactions & $5 \mathrm{mg}$ & $\begin{array}{c}\text { DIS per day } \\
10 \mathrm{mg}\end{array}$ & Total \\
\hline 0 & 8 & 5 & 13 \\
1 & 1 & 3 & 4 \\
2 & 2 & - & 2 \\
3 & 1 & - & 1 \\
Total & 12 & 8 & 20
\end{tabular}

\section{DISCUSSION}

The changes observed in patients receiving small doses of DDS could be considered under the following headings.
Changes in the MI

In almost all the cases in which the MI was available throughout the period of follow-up, it was obvious that the fall in this index was comparable to that observed in patients on conventional doses of DDS. Practically all the cases showed a reduction to zero or near zero in the solid to non-solid ratio in the skin smears.

It is, however, worthy of mention that while the BI was beginning to rise or was steadily rising, there was no corresponding rise in the MI in the cases under review. This is somewhat surprising in view of the currently held opinion that granulated bacilli and non-solid bacilli are not viable (Water and Rees, 1962; Rees and Valentine, 1964). If this be the case, the persistent rise in the BI with a consistently zero or near zero solid: non-solid ratio would be difficult to explain. It is worth emphasizing that at this state we are not able to correlate exactly the MI with the rising $\mathrm{BI}$ in patients receving low doses of DDS.

\section{Changes in BI}

As demonstrated in the graphs for individual patients shown above (Fig. 2) and from Tables 4 and 5, a significantly higher proportion of patients showed either no change or a BI higher than the initial value even after one year of treatment. Comparison between patients on $30 \mathrm{mg}$ and those on $60 \mathrm{mg}$ of DDS per week revealed that a large proportion of patients on $30 \mathrm{mg}$ showed either no change, or an increase in the BI at the end of 12 months. On the other hand, of the patients on $60 \mathrm{mg}$, some showed an initial decline in $\mathrm{BI}$ at the end of the same period, with a tendency for the index to rise as the duration of treatment was prolonged.

Clinical response

In this admittedly small series it is interesting that the clinical improvement generally seen in patients treated with $600 \mathrm{mg}$ of dapsone a week during the initial 6 to 12 months was not seen in patients taking $30 \mathrm{mg}$ DDS per week. Further, we could not record any significant alteration in the skin infiltration and nodular lesions of patients on these small doses during the period of trial. 


\section{Incidence of $E \mathbf{W} L$}

Seven out of the 20 patients under study developed one or more episodes of ENL while receiving the small doses of DDS. We have personally observed that one-third of all the patients with lepromatous leprosy treated with $100 \mathrm{mg}$ of IDIS per day developed ENL during the clinical course of their disease while on treatment (unpublished observation). It appears as though the incidence of ENL is not greatly influenced by the dose of DDS the patient is receiving, to judge by the equal distribution of patients with ENL in the 5, 10 and $100 \mathrm{mg}$ per day dosage-groups in this study.

It should, however, be mentioned that the severity of the ENL on the whole was much less in the smaller-dose group of patients than in patients on the usual dosage of $600 \mathrm{mg}$ per week. In fact, in none of the patients under report was it necessary to terminate the treatment with dapsone because of reaction. In all of them the episodes of reaction could be brought under control either with oral chloroquine or with parenteral stibophen. This is in distinct contrast to our experience in the management of ENL appearing in patients on a dosage of $600 \mathrm{mg}$ of DDS per week. From the limited data available in this study it appears as though the severity of ENI may be dose-related, while the incidence of ENL may be unrelated to dosage. At this point, it is worthy of mention that if ENI, were simply a manifestation of "drug reaction" to sulphone, then the vast majority of our patients with non-lepromatous leprosy, who are taking $600 \mathrm{mg}$ of dapsone per week, should have shown evidence of FNL since they are derived from the same population. It seems as though the appearance of ENL is, in part, a response of the bacillated forms of leprosy, in contra-distinction to the exacerbation that one sees in non-bacillated forms of leprosy under treatment with dapsone. To date, as far as we are aware, there is no record of ENL appearing in patients with non-bacillated types of leprosy. We are therefore unable to substantiate the concept that ENL can be eliminated, or its existence substantially reduced, by reduction in the dosage of sulphone. We are also unable to confirm the expected finding of improvement in the clinical status and bacterial status of patients on small doses of IDDS, namely 30 and $60 \mathrm{mg}$ per week.

The long-term results of this study would indeed be disturbing if they suggested the appearance of resistant strains of bacilli. One fervently hopes that this will not happen because it would be a major disaster in the natural history of leprosy as a whole. In countries where there is no other drug available other than dapsone for the general management of leprosy, appearance of resistance to this "sheet-anchor" of treatment would be an unmitigated diaster! Therefore it would be in order for us to sound a word of caution against the general recommendation of the use of very small doses of dapsone in the routine management of leprosy. If one could restrain the therapeutic enthusiasm dictated by changing fashions, one might obtain more satisfactory long-term results! It is hoped that this presentation might help us all to see the need for more intensive, carefully followed-up, long-term studies to establish the efficacy or otherwise of smaller doses of dapsone, as well as to demonstrate clear-cut advantages of dropping the existing doses of dapsone. In the present state of our knowledge, therefore, one cannot recommend with confidence the small doses of DDS that have been recommended in the past.

\section{SUMMARY}

This paper presents our experience of the use of 30 and $60 \mathrm{mg}$ of dapsone per week in 20 leprosy patients. It appears that the bacterial load tends to increase gradually but progressively in patients treated with small doses of dapsone, in contrast to the gradual decline in bacillary load seen in patients on conventional doses of the drug.

It is interesting to observe that under the conditions of this study, while the BI slowly but steadily increased, there was no corresponding rise in the MI. From the data presented here, one is unable to substantiate the concept that all non-solid bacilli are non-viable. 
No significant reduction in the incidence of ENL among patients on 30 and $60 \mathrm{mg}$ DDS per week could be demonstrated; it has been observed that the severity of "reaction" (FNL) appears to be significantly reduced in patients on smaller doses of dapsone, as compared with patients receiving $600 \mathrm{mg}$ of DDS per week.

A word of caution is offered regarding the widespread use of smaller doses of DIDS. It is suggested that adoption of this policy be deferred until further studies in small groups of patients on a long-term basis have confirmed the advantages of such a regime and have dispelled the fear of possible development of resistance to dapsone on a mass scale.

\section{ACKNOWLEDGMENTS}

We should like to place on record our indebtedness to Mr. J. Fowler and Mr. Sundaram for technical assistance in the reading of the skin smears, and to thank Mr. E. Raj Kumar for the graphs and Mrs. Furness, Mr. P. L. N. Reddy and Mr. S. Philip for secretarial assistance.

We are grateful to the American Leprosy Mission, New York, and the leprosy Mission, London, for financial support and encouragement.

\section{REFERENCES}

BROWNE, S. G. (1965). Low dose oral dapsone. Interim report. Lepr. India 37, 299 .

COCHRANE, R. G. (1963). Complicating conditions due to leprosy. In Leprosy in Theory and Practice, p. 337. Ed. R. G. Cochrane. Bristol: John Wright.
FAGET, G. H., POGGE, R. C., JOHANSEN, F. A., DINAN, J. F., PREJEAN, B. M. and ECCLES, C. G. (1943). The promin treatment of leprosy. A progress report. Publ. Hlth Rep., Wash. 58, 1729.

FAGET, G. H. and POGGE, R. C. (1944). The therapeutic effect of promin in leprosy. Publ. Hlth Rep., Wash. $60,1165$.

FAGET, G. H. and PogGE, R. C. (1945). Treatment of leprosy with diasone. New Orl. med. surg. .J. 98, 145.

JAMES, A. D., JOSE, G. T., RICARDO, S. G., JOSE, N. R., LEOPOLDO, M. L., JUAN, V. F. and TAJARDO, T. T. (1967). Clinical evaluation studies in lepromatous leprosy. Int. J. Lepr. 35, 128.

MUIR, E. (1944). Preliminary report on diasone in the treatment of leprosy. Int. .J. Lepr. 12, 1.

PEтtit, J. H. S. and REES, R. J. W. (1967). Chemotherapeutic trials in leprosy. 4. Dapsone (IDI)S) in low dosage in the treatment of lepromatous leprosy. A demonstration pilot trial. Int. .J. Lepr. 35, 140.

RAMU, G. and RAMANUJAM, k. (1965). Chemotherapy of leprosy. Lepr. India 37 (Suppl. 3a), 1.

REES, R. J. W. (1967). A preliminary review of the experimental evaluation of drugs for the treatment of leprosy. Trans. R. Soc. trop. Med. Hyg. 61, 581.

REES, R. J. W. and valentine, R. C. (1964). The submicroscopical structure of the Mycobacterium leprae. In Leprosy in Theory and I'ractice, end ed., pp. 30-35. Ed. R. G. Cochrane. Bristol: John Wright.

SHEPARD, C. C., MCRAE. D. H. and HABAS, I. A. (1!)(i6). Sensitivity of Mycobacterium leprae to low levels of 4.4'-diaminodiphenylsulfone. Proc. Soc. exp. Biol. Med. 122, 893 .

SHEPARD, C. C. and CHANG, Y. T. (1967). Effect of DDS on established infections with Mycobacterium leprae in mice. Int. .J. Lepr. 35, 52.

SHEPARD, C. C. (1967). Studies in mice of the action of IDIS against $M$ ycobacterium leprae. Int. .J. Lepr. 35, (i) 16 .

WAters, M. F. R. and REES, R. J. W. (1962). Changes in morphology of Mycobacterium leprae in patients under treatment. Int. .J. Lepr. 30, 26.

WATERS, M. F. R., REES, R. J. W. and ELLARD, G. A. (1968). Ninth International Leprosy Congress, London. Abstract No. 196. 